(C) 2017 IEEE. Personal use of this material is permitted. Permission from IEEE must be obtained for all other uses, in any current or future media, including reprinting/republishing this material for advertising or promotional purposes, creating new collective works, for resale or redistribution to servers or lists, or reuse of any copyrighted component of this work in other works. 


\title{
Windowed SHE-PWM of Interleaved Four-Quadrant Converters for Resonance Suppression in Traction Power Supply Systems
}

\author{
Kejian Song, Georgios Konstantinou, Member, IEEE, Wu Mingli*, Pablo Acuna, Member, IEEE, \\ Ricardo P. Aguilera, Member, IEEE, and Vassilios G. Agelidis, Fellow, IEEE
}

\begin{abstract}
AC electric locomotives that use a number of interleaved four-quadrant converters $(4 \mathrm{QCs})$ generate high frequency switching harmonics which may stimulate certain resonances in traction power supply systems (TPSSs). A windowed selective harmonic elimination pulse-width modulation (SHE-PWM) method is proposed to suppress such resonances. Owing to the windowed design and the precalculated solutions, the proposed method covers the wide potential resonant frequency range and addresses the resonant frequency variation while keeping the low switching frequency of the traction converters. The proposed windowed SHE-PWM is fully tested with a closedloop controller in a simulation model with the TPSS and the ac electric locomotive. Comparative simulation results show that the windowed SHE-PWM is an effective alternative that overcomes the resonance suppression limitations of the conventional phase-shifted PWM (PS-PWM). The performance of proposed windowed SHE-PWM on an experimental equivalent resonant circuit is further evaluated and compared with PS-PWM. Both simulation and experimental results verify the effectiveness and feasibility of the proposed method.
\end{abstract}

Index Terms-AC electric locomotives, power electronics converters, resonance, selective harmonic elimination PWM, traction power supply system.

\section{INTRODUCTION}

W ITH the development of high power semiconductor devices and advanced control techniques for power electronics converters, ac-drives have become the most popular choice in traction applications globally [1]-[5]. In China, most freight service railways adopt the $\mathrm{HX}_{\mathrm{D}}$ series ac electric locomotives, while all high-speed railways (HSRs) use the CRH series electric multiple units (EMUs). Both of the above locomotives and EMUs use a number of interleaved fourquadrant converters $(4 \mathrm{QCs})$ as front-end rectifiers to either draw power from the supply network or inject power back into the supply network during regenerative braking [6]-[9].

Kejian Song and Wu Mingli* are with the School of Electrical Engineering, Beijing Jiaotong University, Beijing 100044, China (e-mail: 12117360@bjtu.edu.cn; mlwu@bjtu.edu.cn).

G. Konstantinou and P. Acuna are with the School of Electrical Engineering and Telecommunications, The University of New South Wales, Sydney, NSW 2052, Australia (e-mail: g.konstantinou@unsw.edu.au; pablo.acuna@unsw.edu.au)

R. P. Aguilera is with the School of Electrical, Mechanical and Mechatronic Systems, University of Technology Sydney, Sydney, NSW 2007, Australia (email: raguilera@ieee.org).

V. G. Agelidis is with the Department of Electrical Engineering, Technical University of Denmark, $2800 \mathrm{Kgs,} \mathrm{Lyngby,} \mathrm{Denmark} \mathrm{(email:}$ vasagel@elektro.dtu.dk).

\section{A. Resonance in Traction Power Supply Systems}

Compared with the diode and/or thyristor rectifiers of traditional dc electric locomotives [5], the 4QCs ensure unity power factor and a nearly purely sinusoidal current on the network-side. However, the interleaved $4 \mathrm{QCs}$, operating under phase-shifted pulse-width modulation (PS-PWM), still generate a fixed spectrum containing a relatively high amount of sideband harmonics located around the multiples of the carrier frequency. If some of the injected current harmonics, generated by the PWM converters, coincide with the resonant frequency of the traction power supply system (TPSS), a resonance will be prone to be stimulated [10], [11]. When a resonance occurs, amplified resonant voltage and current appear in the TPSS, resulting in supply voltage distortion, interference with adjacent communication lines, erroneous operation of protective devices, or even damaging in some high-voltage devices [12], [13]. Typical resonance cases on Chinese railways, occurred in recent years, are summarized in Table I.

The resonance phenomenon has been analyzed through traveling wave theory [14], and a method for on-line identification of the resonance frequency was proposed in [15]. Two different approaches to deal with this issue were provided in [16], [17]. However, the German railways that were studied in [14]-[17] have their own TPSS features which are far from the counterparts in many other countries. Moreover, the 4QC and associated control techniques have seen a great deal of development during the past two decades. Recently, more researchers reported their studies on the TPSS resonance, e.g. [11]-[13], [18]-[21]. Most studies focus on the mechanism of the resonance, and try to illustrate the factors that influence the resonance such as the length of supply section, the position of the vehicle and the distribution of the resonant harmonics in the TPSS through deriving the impedance-frequency characteristic of the TPSS [19]-[21].

\section{B. Resonance Suppression Approaches}

A number of approaches can be adopted for resonance suppression in TPSSs. Some older types of ac locomotives and EMUs were equipped with high-pass passive filters (e.g. $\mathrm{RC}$ branch) to eliminate the high-frequency harmonics [14]. Considering requirements for light weight and reliability, this method is abandoned in many modern ac-drive railway 
TABLE I

RESONANCE CASES ON CHINESE RaILWAys

\begin{tabular}{|c|c|c|c|}
\hline Vehicle type & Frequency $(\mathrm{Hz})$ & Time & Location \\
\hline CRH2 & $1050-1250$ & Aug. 2008 & Wuqing - Yongle \\
\hline $\mathrm{HX}_{\mathrm{D}} 3$ & $850-1050$ & Mar. 2010 & Macheng - Wuhan \\
\hline CRH380A & $2250-2750$ & Jan. 2011 & Guangzhounan Station \\
\hline $\mathrm{HX}_{\mathrm{D}} 3 \mathrm{~B}$ & $1150-1450$ & Dec. 2011 & Shanhaiguan Station \\
\hline $\mathrm{HX}_{\mathrm{D}} 1 \mathrm{~B}$ & $2650-2750$ & Dec. 2013 & Jiujiangxi - Mahuiling \\
\hline $\mathrm{HX}_{\mathrm{D}} 21000$ & $2050-2450$ & Nov. 2014 & Wulipu Station \\
\hline
\end{tabular}

vehicles. An alternative is installing high-pass passive filters in electrical substations (ESSs) or section posts (SPs) [13], [22], [23]. The passive filters can filter out most of the highfrequency harmonics on the supply network but also move the resonant frequency of the TPSS without any extra circuits on board. However, the bulky ground passive filter equipment increases both cost and space requirements. Active power filters (APFs), with their advantages compared to passive filters, can be used on board the train or installed on the ground to suppress the harmonic propagation on the supply network as documented in the literature [17], [24], [25]. In practice, APFs are currently mature for eliminating lowerorder harmonics compared to the sideband harmonics, while the extra cost and reliability can be potential problems for APFs in traction applications.

On the other hand, a proper modulation method that does not generate the resonant frequency harmonics can avoid the resonance potential without any extra drawbacks of the aforementioned approaches [16]. With the additional advantage of tight spectrum control, selective harmonic elimination PWM (SHE-PWM) can be redefined to address the TPSS resonance problem. In [26], SHE-PWM was initially introduced for two interleaved EMU 4QCs. Although the desired SHE-PWM spectrum performance was obtained, the method did not consider the resonance issue. A resonant harmonic elimination PWM (RHEPWM) method for four interleaved EMU 4QCs was presented in [18]. Essentially, the RHEPWM is a SHE-PWM used for resonant harmonic elimination. This modulation scheme provided a fixed SHE-PWM pattern for a specific resonant frequency but fail to consider the resonant frequency variation [11], [14], [19], [20]. In general, the resonant frequency changes since the train travels across different supply sections. Moreover, the SHE-PWM patterns of the four 4QCs, proposed in [18], have different numbers of commutation angles.

Most of the recent resonance studies, e.g. [11], [13], [18][21], focus on EMUs operating on HSRs especially the Chinese cases. The fact is that most of Chinese EMUs are equipped with eight to fourteen $4 \mathrm{QCs}$, and, nevertheless, the ac electric locomotives are equipped with only four, six or eight 4QCs. Therefore, when PS-PWM schemes are well designed, the sideband harmonic frequencies of EMUs will be very high easy to avoid the resonance. On the contrary, the sidebands of ac electric locomotives, with relatively low frequencies, will be easier to stimulate TPSS resonances. Therefore, more attention

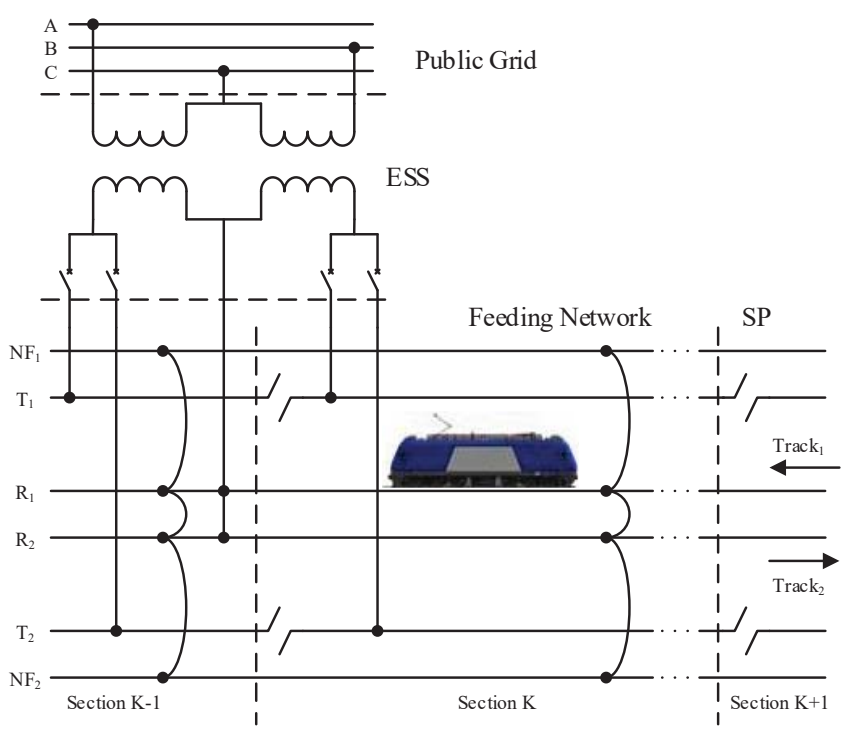

Fig. 1. Configuration of a double-track T-R+NF TPSS. Track 1 : uplink, Track $_{2}$ : downlink.

should be paid to the ac electric locomotives which are widely running on conventional Chinese railways.

This work is aimed to propose a windowed SHE-PWM technique to suppress TPSS resonances, considering a typical ac electric locomotive with four interleaved $4 \mathrm{QCs}$. To address this issue, five harmonic free frequency windows are precalculated to account for the potential resonant frequency range and to deal with the resonant frequency variation that depends on the particular TPSS section that the train is running. The rest of this paper is organized as follows. Section II briefly analyzes the mechanism of the TPSS resonance. In Section III, the general formulation of SHE-PWM for interleaved converters is described and then a windowed SHE-PWM technique for four interleaved $4 \mathrm{QCs}$ is proposed. Section IV describes the implementation of the proposed method. Section $\mathrm{V}$ provides simulation and experimental results to validate the windowed SHE-PWM. Conclusions of this work are summarized in Section VI. Descriptions and parameters of a typical TPSS studied in this work are presented in Appendices A and B.

\section{Resonance Mechanism in Traction Power SUPPLY SYSTEMS}

The overall structure of a double-track direct feeding system with return wire (T-R+NF) TPSS, which is widely used in conventional Chinese railways, is presented in Fig. 1. This minimum TPSS consists of an ESS, a feeding network section and a SP. An ac electric locomotive acts as a nonlinear load injecting harmonics into the TPSS. In the ESS, a Vv connection transformer is commonly used to draw power from three-phase public grid $(110 \mathrm{kV}$ or $220 \mathrm{kV})$ supplying two sections. The SP located at the end of a section electrically divides the feeding network.

Treating the locomotive as a constant harmonic current source is not explicit to illustrate the coupling relationship 


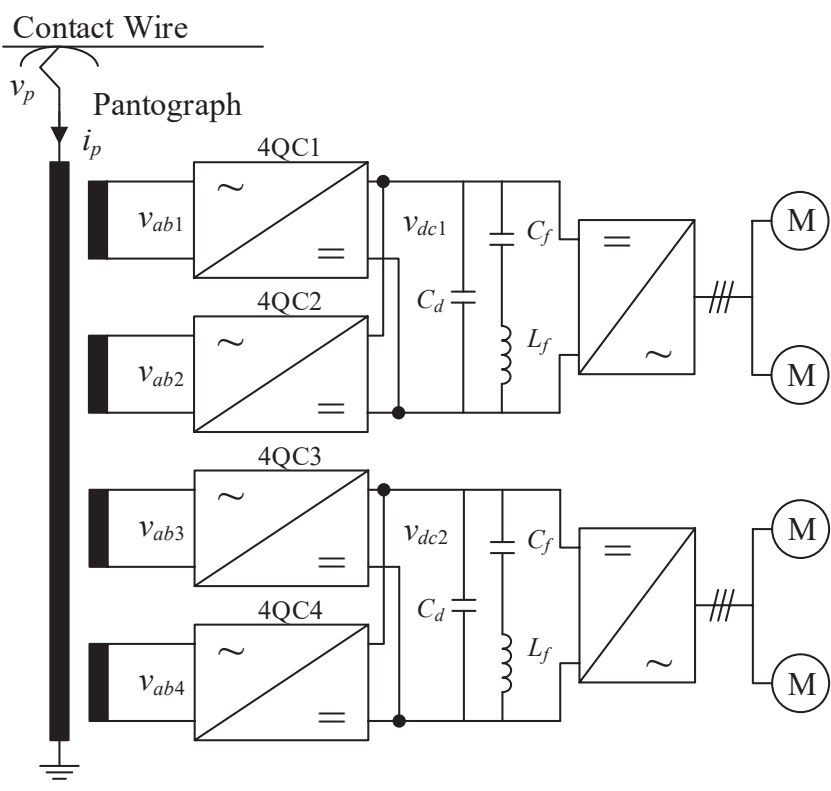

Fig. 2. Configuration of a typical ac electric locomotive drive system.

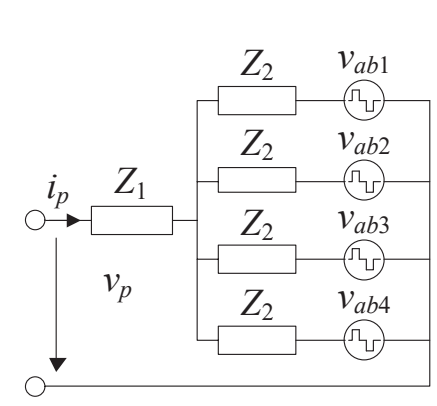

(a)

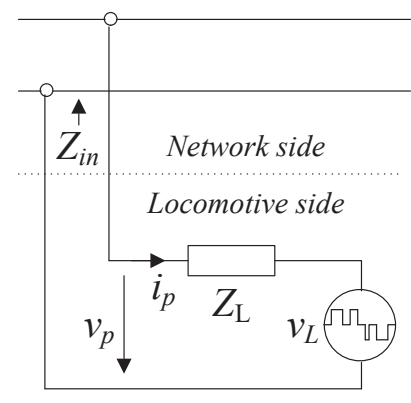

(b)
Fig. 3. Network-side model of ac locomotive, (a) Equivalent circuit, (b) Thévenin model coupling with the TPSS.

between the TPSS and the locomotive for the purpose of studying the resonance. A detailed model of an ac locomotive should be built according to the electrical structure of its acdrive system. A typical configuration of the ac locomotive drive system is given in Fig. 2. Four 4QCs, with the same topology of single-phase H-bridge converter, are interleaved via an on-board step-down transformer to draw power from the feeding network through a pantograph. Here, $v_{a b i}(i=1$, $2, \ldots, 4)$ denotes the 4QC ac-side voltage, while $v_{p}$ and $i_{p}$ represent the voltage and current at the pantograph. Two of the 4QCs share a common dc-link providing constant voltage for a three-phase inverter driving the induction motors. Additionally, $v_{d c 1}$ and $v_{d c 2}$ stand for the two dc-link voltages, $C_{d}$ is the support capacitor, $C_{f}$ and $L_{f}$ behave as a second harmonic filter branch in a dc-link.

Since the four secondary windings of the transformer are considered independent and decoupled, the locomotive network-side model can be represented by using an equivalent circuit as shown in Fig. 3(a). To simplify the analysis, the transformer turn ratio is assumed 1:1 hereinafter. $Z_{1}$ and $Z_{2}$ represent the leakage impedances of the transformer primary and secondary windings, respectively. The circuit can be simplified to a Thévenin model with an equivalent voltage source and impedance, respectively:

$$
\begin{gathered}
v_{L}=\frac{v_{a b}}{4}=\frac{\sum_{i=1}^{4} v_{a b i}}{4}, \\
Z_{L}(j \omega)=Z_{1}(j \omega)+\frac{Z_{2}(j \omega)}{4},
\end{gathered}
$$

where $v_{a b}$ is the combined ac-side voltage of the four interleaved 4QCs. Consequently, the coupling relationship between the ac locomotive and the TPSS is depicted in Fig. 3(b) where $Z_{\text {in }}$ stands for the input impedance of the TPSS seen from the pantograph. Neglecting the background harmonics, a $k$-th harmonic $v_{L k}$ of the equivalent voltage generates a harmonic voltage at the pantograph:

$$
v_{p k}=\frac{Z_{i n}\left(j k \omega_{1}\right)}{Z_{i n}\left(j k \omega_{1}\right)+Z_{L}\left(j k \omega_{1}\right)} v_{L k},
$$

where $\omega_{1}$ stands for the fundamental angular frequency. According to the analysis above, the following remarks can be obtained.

Remark I: Both the equivalent impedances of the TPSS and the locomotive, $Z_{i n}$ and $Z_{L}$, create a coupling impedance system with one or more resonant frequencies ${ }^{1}$. The composite voltage $v_{a b}$ contains higher-order harmonics which may coincide with the resonant frequency stimulating very high harmonic voltage at the pantograph, $v_{p k}$, causing a series detrimental effects, which is collectively referred to as TPSS resonance.

Remark II: The equivalent impedance, $Z_{i n}$, of TPSS refers to the impedance-frequency characteristics of the ESS and the feeding network. The SP provides no impedance but defines the length of a TPSS that affects $Z_{i n}$ as well as the resonant frequency. Modeling the complex TPSS in frequency domain is another attractive aspect of the resonance research which is significant to get a comprehensive understanding of the resonance. Brief descriptions and parameters of the ESS and the feeding network studied in this paper are given in Appendices A and B, respectively.

\section{Proposed Windowed Selective Harmonic ELIMINATION PWM}

\section{A. General Formulation of SHE-PWM for Multiple Inter- leaved Converters}

SHE-PWM provides a tight control of the harmonic spectrum of a given PWM voltage waveform [27]. The acquisition, continuity and range of the available solutions depend on the formulation of the SHE-PWM problem for a particular application and converter. Interested readers are referred to [28]

\footnotetext{
${ }^{1}$ Typically, there are more than one resonant frequencies in a TPSS [14], [20]. The lowest resonant frequency is the one that is easily within the range of the PWM harmonics of lower sideband groups (see Table I for such examples). This can have detrimental effects on the operation of the system and is the main concern of this article. The impact of other resonant frequencies to the system is negligible and is not linked to the PWM.
} 
for a detailed mathematical analysis of multilevel SHE-PWM. In the case of $k$ interleaved three-level $\mathrm{H}$-bridge converters, the problem is formulated individually for the fundamental frequency component of each converter, while higher-order harmonic elimination is achieved for the combined multilevel waveform. Assuming quarter-wave (QW) symmetry with $N$ transitions (switching angles) per quarter-period, per-bridge, the fundamental frequency components can be written as:

$$
\begin{gathered}
\left(\sum_{i=1}^{N}(-1)^{i} \cos \alpha_{i}-M_{1}\right)^{2}+\left(\sum_{i=N+1}^{2 N}(-1)^{i+1} \cos \alpha_{i}-M_{2}\right)^{2} \\
+\ldots+\left(\sum_{i=(k-1) N+1}^{k N}(-1)^{i} \cos \alpha_{i}-M_{k}\right)^{2}=0
\end{gathered}
$$

where $M_{k}$ is the modulation index corresponding to the $k$-th converter, and the higher-order harmonics as:

$$
\begin{aligned}
b_{n}=\left[\sum_{i=1}^{N}(-1)^{i} \cos n \alpha_{i}\right. & +\sum_{i=N+1}^{2 N}(-1)^{i+1} \cos n \alpha_{i}+\ldots \\
& \left.+\sum_{i=(k-1) N+1}^{k N}(-1)^{i} \cos n \alpha_{i}\right]^{2},
\end{aligned}
$$

Typically, the system operates with equal modulation indices in all the bridges so that $M_{1}=M_{2}=\ldots=M_{k}=M$. For a single-phase output voltage, $M$ is generally governed by:

$$
M=\frac{\pi}{4 V_{d c}} \hat{V}_{1}
$$

where $\hat{V}_{1}$ and $V_{d c}$ are the target fundamental component and dc voltage, respectively. The restrictions for the angles, in order to derive a feasible three-level waveform, are independently applied for each bridge so that:

$$
\begin{aligned}
& 0<\alpha_{1}<\alpha_{2}<\ldots<\alpha_{N}<\pi / 2, \\
& 0<\alpha_{N+1}<\alpha_{N+2}<\ldots<\alpha_{2 N}<\pi / 2, \\
& \ldots \\
& \quad 0<\alpha_{(k-1) N+1}<\alpha_{(k-1) N+2}<\ldots<\alpha_{k N}<\pi / 2 .
\end{aligned}
$$

A total of $k N$ angles are available for the control of the fundamental frequency and the elimination of the higher-order harmonics. A number of $k$ harmonics are required to control the fundamental frequency of each converter, while maximum $k(N-1)$ additional high-order harmonics can be eliminated. The solutions to the SHE-PWM problem can be found through an iterative minimization/optimisation process of the total harmonic spectrum so that (4) and (5) are simultaneously equal to zero, following the set of restrictions of (7) [28]. A typical issue with SHE-PWM for multiple interleaved and multilevel converters is that the range and continuity of solutions are quite limited [29]. To improve both of these aspects, the number of harmonics that are eliminated can be reduced from the maximum number of $k(N-1)$ harmonics by one or two, effectively relaxing the requirements of the SHE-PWM problem.

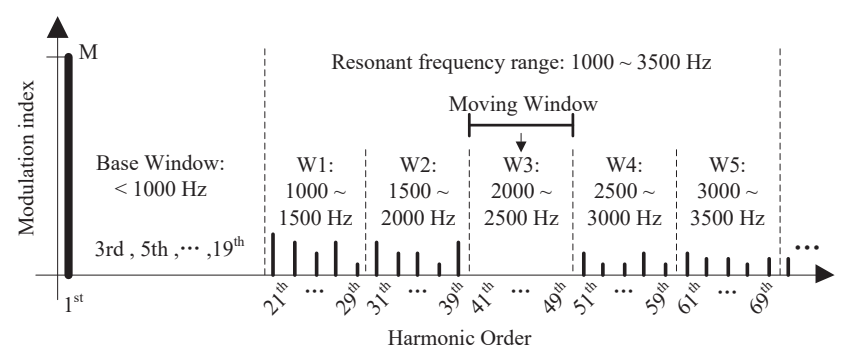

Fig. 4. Concept of windowed SHE-PWM utilising W3, eliminating resonant harmonics between 2000 and $2500 \mathrm{~Hz}$.

\section{B. Windowed SHE-PWM}

In order to address the resonance issue that may potentially appear in the coupling system of the TPSS and the locomotive, the SHE-PWM problem is reformulated so that both loworder harmonics as well as harmonics around the resonant frequency are eliminated. However, the resonant frequency is not constant but depends on the TPSS section the locomotive is located. Thus, a fixed SHE-PWM cannot tackle the resonant frequency variation. To address all the problems described above, a windowed SHE-PWM method featuring a base window plus a moving window is proposed in this paper as shown in Fig. 4.

For the windowed SHE-PWM, two distinct windows of eliminated harmonics are defined. The base window is fixed at low frequency range. Inside this window the fundamental frequency components are controlled to $M$ and all the odd harmonics are eliminated. The moving window which addresses the resonance for a particular TPSS section and moves accordingly. The frequency range of the resonances is split into several sub-regions; each of them with a width equal to the moving window. When the resonant frequency is in a subregion, all harmonics within the window are eliminated.

As discussed earlier, the design of the windowed SHE-PWM depends on the number of commutation angles that can be used to control harmonics. Considering a typical locomotive, as described previously, with 4 interleaved single-phase H-bridge converters conventionally operating with carrier frequencies between 250 and $450 \mathrm{~Hz}$. Accordingly, $k=4$ and $N=5$ are considered in this study so that a total of 20 angles can be used to formulate the SHE-PWM problem. Out of the 20 angles, i) 4 angles are required to handle the fundamental frequency components of the four bridges, ii) 2 angles are discarded for relaxing the problem restrictions [29], and iii) 14 angles are used to eliminate harmonics including 9 low-order harmonics (from the 3 rd to the 19th) in the base window and 5 harmonics in the moving window.

According to the previous angle arrangements, the proposed SHE-PWM is defined as shown in Fig. 4. The base window frequency range is up to $1000 \mathrm{~Hz}$. The moving window has a width of $500 \mathrm{~Hz}$ and is selected based on the potential resonant frequency range (from 1000 to $3500 \mathrm{~Hz}$ ). Hence, a total of 5 sub-regions (W1, W2,..., W5) are required. For instance, in Fig. 4, when the resonant frequency is within window W3, the 5 angles of the moving window are used to eliminate the odd 
harmonics between 2000 and $2500 \mathrm{~Hz}$. In order to avoid the impact of large non-eliminated harmonics that may be excited by resonant frequencies, an overlap between the two windows can also be considered. Alternatively, the multiple solutions of the windowed SHE-PWM problem can be evaluated and those with relatively high non-eliminated harmonics near the windows can be penalized / discarded.

The windowed SHE-PWM problem is transcendental in nature and exhibits multiple solutions. Considering the base and moving windows of Section III-B and Fig. 4, the problem is formulated and a unique set of solutions for the switching patterns of the four $\mathrm{H}$-bridges that covers all five of the windows is shown in Fig. 5. The reduction by two in the number of eliminated high-order harmonics facilitates the acquisition and the continuity of the acquired solutions at the cost of harmonic performance for SHE-PWM technique.

\section{IMPLEMENTATION}

Closed-loop implementation of a SHE-PWM technique is not a trivial issue, and in this section, a full implementation of the proposed windowed SHE-PWM method is developed in the $d q$ frame.

The proposed SHE-PWM pattern is calculated to steer the composite voltage $v_{a b}$ rather than any single $4 \mathrm{QC}$ ac-side voltage $v_{a b i}$. Therefore, a unified virtual converter, representing the equivalent behavior of the 4 interleaved 4QCs, is defined as the control objective for a master controller (Fig. 6(a)). Here, $L$ and $r$ stand for the leakage inductance and resistance of the transformer, as seen from one of the secondary windings. The voltage $v_{d c}$ is the artificial total dc-link voltage. Note that the unified virtual converter is based on assumptions: i) the 4 interleaved 4QCs have identical circuits, ii) generally the 4QCs equally share the traction load so that assuming $v_{d c}=v_{d c 1}=$ $v_{d c 2}$, similar to $M_{1}=M_{2}=\ldots=M_{k}=M$ mentioned before. The master controller handles the line current of the locomotive $i_{p}$, while synchronizing it with $v_{p}$ through regulating the composite voltage $v_{a b}$ as a SHE-PWM pattern. A standard second order generalized integrator phase-locked loop (SOGI-PLL) is used to synchronize with the supply voltage $v_{p}$. A standard PI controller is used to regulate $v_{d c}$ generating the reference current $i_{p d}^{*}$. A $d q$-based single-phase current controller, that uses an improved orthogonal signal generation (OSG) method adopted from [30], synthesizes the modulation index $(M)$ and phase angle $(\theta)$ of the target composite voltage in order to generate the SHE pattern [28], [31].

The implementation of the windowed SHE-PWM is presented in Fig. 6(b). The proposed SHE pattern is defined as a function with three parameters: $\operatorname{SHE}(W, M, \theta)$. Conventionally, $M$ and $\theta$ are used to read the SHE look-up table that generates the switching signals for the 4QCs [28]. An additional parameter $W \in(1,2, \ldots, 5)$, for resonance identification (Res. ID), is introduced to address the resonant frequency variation. When the resonant frequency is identified in the range of $\mathrm{W} j(j \in(1,2, \ldots, 5)), W$ is set to $j$ so that $\mathrm{W} j$ is

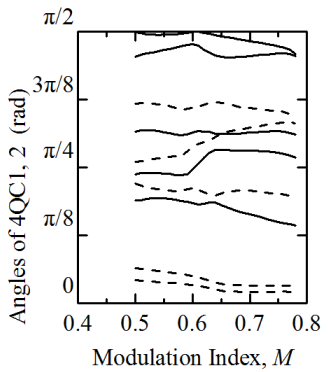

(a)

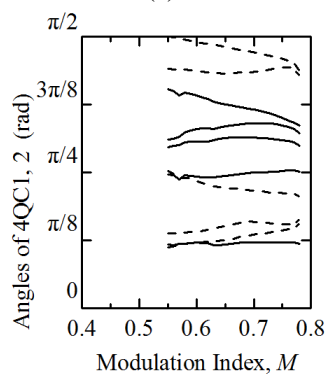

(c)

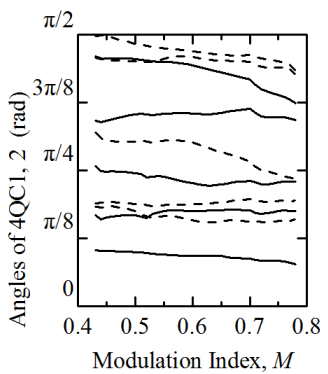

(e)

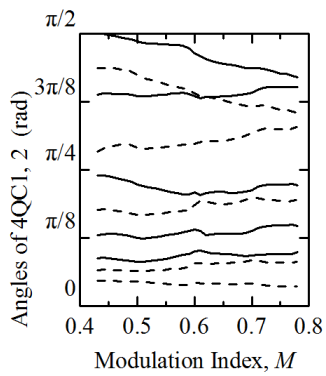

(g)

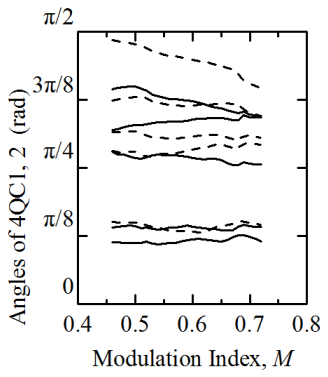

(i)

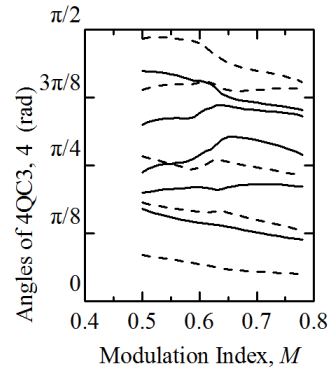

(b)

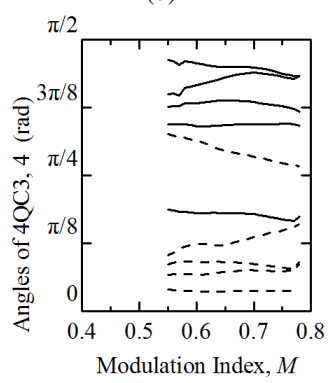

(d)

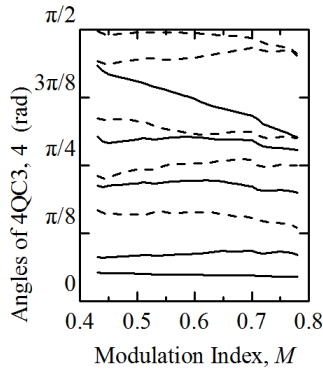

(f)

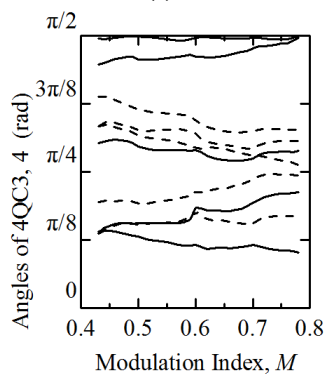

(h)

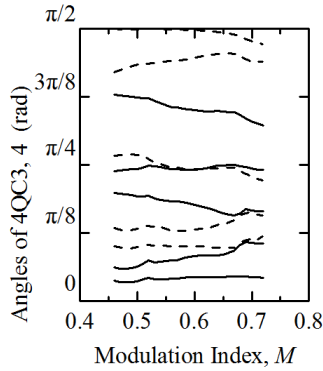

(j)
Fig. 5. Windowed SHE-PWM solutions. (a) and (b): W1, (c) and (d): W2, (e) and (f): W3, (g) and (h): W4, (i) and (j): W5. Solid line: angles of 4QC1 and 4QC3, Dashed line: angles of 4QC2 and 4QC4. 


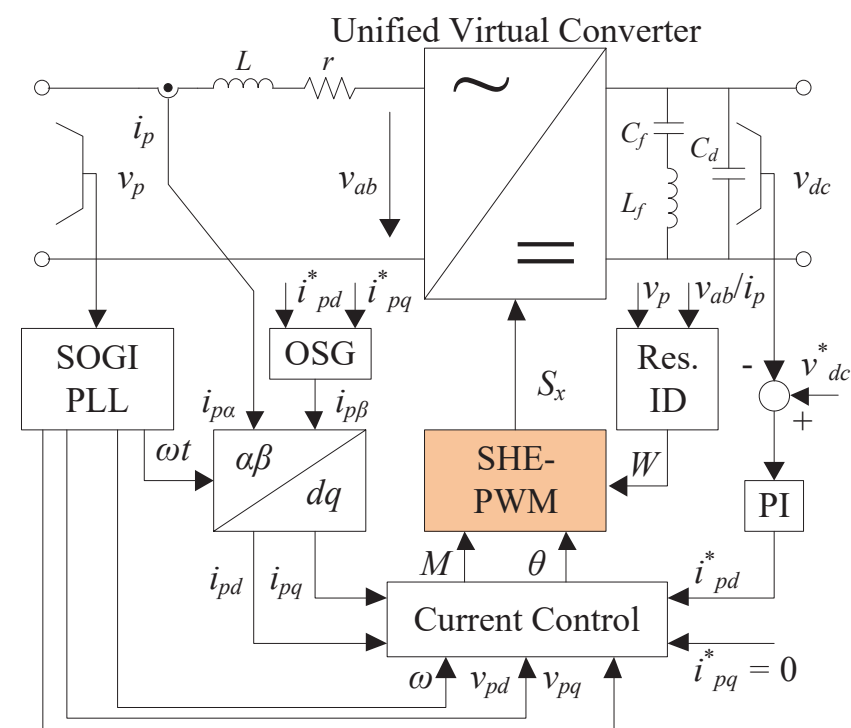

(a)

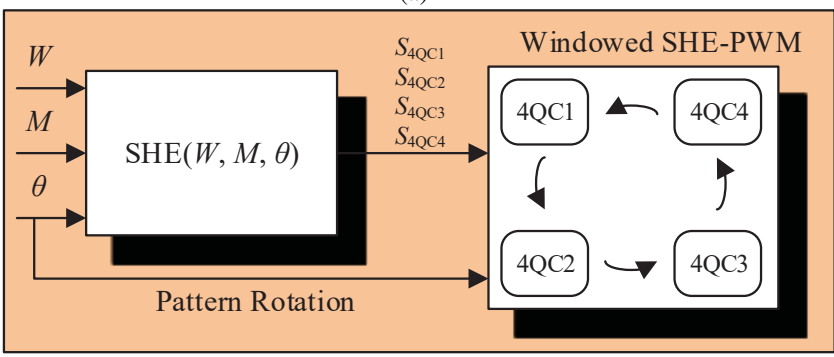

(b)

Fig. 6. Full implementation: (a) Unified virtual converter and its master controller, (b) Windowed SHE-PWM.

selected as the moving window ${ }^{2}$. According to operational data and measurement experience in field the TPSSs, the resonant frequency remains constant when the locomotive runs inside a same supply section so that the window changes infrequently. Another issue that should be noted is that when using the SHEPWM the four 4QCs have different switching patterns during a fundamental period. To avoid the potentially unbalanced thermal distribution, the order of the $4 \mathrm{QCs}$ is rotated every fundamental period along with $\theta$.

\section{Results}

In this section, simulation and experimental results, necessary to validate the effectiveness and the feasibility of the windowed SHE-PWM of interleaved 4QCs for resonance suppression, are presented.

\section{A. Comparative Simulation Study}

The coupling system of the TPSS and the locomotive is modeled through Matlab/Simulink. The locomotive model,

\footnotetext{
${ }^{2}$ The extremum value of the ratio $\frac{v_{p}(j \omega)}{v_{a b}(j \omega)}$ or $\frac{v_{p}(j \omega)}{i_{p}(j \omega)}$ can be used to identify the resonant frequency, since these values reflect the harmonic amplification. An on-line resonance identification method was documented in detail in [15]. Such methods are out of the scope of this work.
}

TABLE II

Electrical PARAmeters OF THE Locomotive Model

\begin{tabular}{ccc}
\hline \hline Parameter & Description & Value \\
\hline$P_{N}$ & Rated output power & $4800 \mathrm{~kW}$ \\
$N_{T}$ & Transformer turns ratio & $25000 \mathrm{~V}: 970 \mathrm{~V}$ \\
$L$ & AC filter inductance & $1.75 \mathrm{mH}$ \\
$r$ & AC filter resistance & $0.05 \Omega$ \\
$V_{d c}^{*}$ & DC-link voltage reference & $1800 \mathrm{~V}$ \\
$C_{d}$ & DC-link support capacitance & $12 \mathrm{mF}$ \\
$C_{f}$ & Capacitance of second harmonic filter & $9.85 \mathrm{mF}$ \\
$L_{f}$ & Inductance of second harmonic filter & $0.257 \mathrm{mH}$ \\
\hline
\end{tabular}

including the on-board transformer and four interleaved 4QCs, is based on the configuration of Fig. 2 and its electrical parameters are listed in Table II. The inverters and motors are seen as resistive loads governed by the dc-link voltage and output power. The double-track T-R+NF TPSS model is developed according to the ESS and the feeding network parameters of Appendices A and B. Simulation results of the windowed SHE-PWM are presented and compared with those of PS-PWM (250 Hz carrier frequency).

1) Test1 $24 \mathrm{~km}$ Section, W2: A first test is executed on a $24 \mathrm{~km}$ long TPSS section model. Steady-state simulation results of PS-PWM and windowed SHE-PWM are given in Figs. 7 and 8, respectively, when the locomotive model operated at rated power.

Using the conventional PS-PWM, a resonance occurs and the pantograph voltage $v_{p}$ is distorted seriously, as shown in Fig. 7(a). According to Figs 7(b) and (d), the combined pulse voltage $v_{a b}$ contains a sideband harmonic of $1550 \mathrm{~Hz}$ (31st), $168.5 \mathrm{~V}$ (3.5\% of fundamental) which coincides with the resonant frequency stimulating the TPSS resonance. Consequently, as shown in Fig. 7(c), the 31st harmonic is amplified to $4.19 \mathrm{kV}$ in $v_{p}$ and the total harmonic distortion (THD) of this supply voltage increases to $15.6 \%$. Furthermore, harmonics near the 31 st are amplified as well because of the relatively high impedance values of the frequencies close to the resonant frequency.

The resonance is suppressed by adopting the windowed SHE-PWM with the moving window on W2. As shown in Fig. 8(a), $v_{p}$ is significantly less distorted than that of PSPWM. Figs. 8(b) and (d), provide the waveform and spectrum of $v_{a b}$ in which the harmonics of both base window (up to $1000 \mathrm{~Hz}$ ) and moving window (from 1500 to $2000 \mathrm{~Hz}$ ) are nearly completely eliminated. Although some harmonics out of those ranges are generated, they are at uncritical frequencies and, thus, the spectrum of Fig. 8(c) contains few harmonics out of the base and moving windows. The THD of $v_{p}$ decreases to only $2.53 \%$.

Additionally, the pantograph current $\left(i_{p}\right)$ waveforms of both Figs. 7(a) and 8(a) are sinusoidal and in phase with $v_{p}$. Using the proposed SHE-PWM with W2, a step change in the output power from half to full of the rated one is shown in Fig. 9. The dc-link voltages (Fig. 9(a)) and ac-side current (Fig. 9(b)) take about $125 \mathrm{~ms}$ to reach their new equilibrium points, so that 


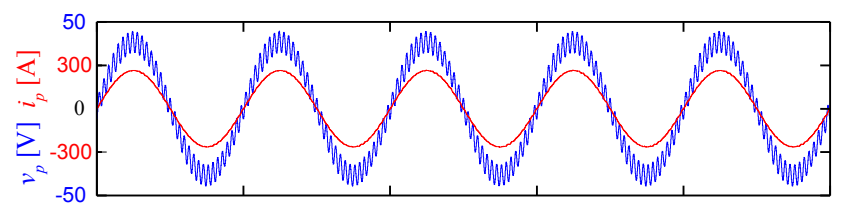

(a)

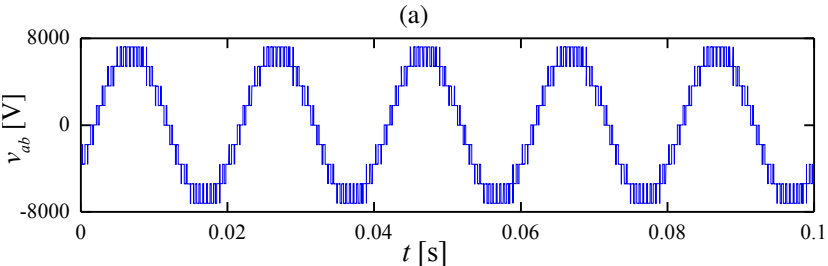

(b)

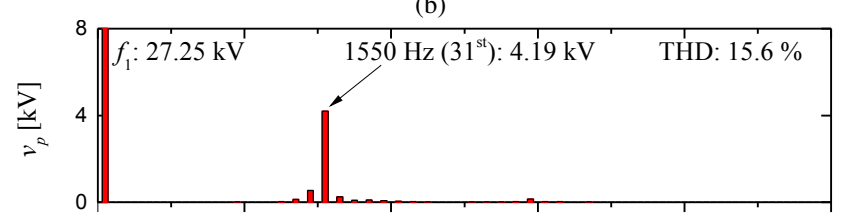

(c)

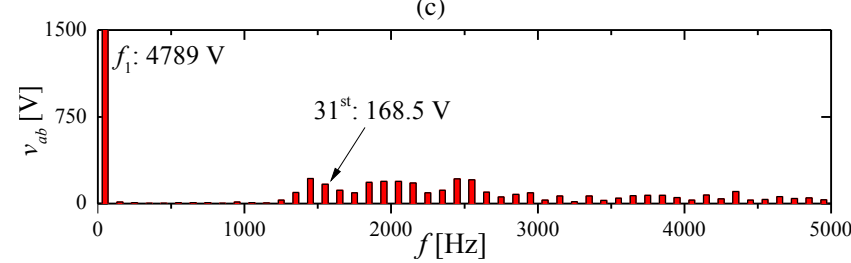

(d)

Fig. 7. Simulation result of PS-PWM, (a) waveforms of $v_{p}$ and $i_{p}$, (b) waveform of $v_{a b}$, (c) spectrum of $v_{p}$, (d) spectrum of $v_{a b}$.

both steady-state and dynamic performances of the controller are verified.

2) Test2 $14 \mathrm{~km}$ Section, W3: A second test is executed on a $14 \mathrm{~km}$ long TPSS section model. Similarly, steady-state simulation results of PS-PWM and windowed SHE-PWM with the moving window on W3 are given in Figs. 10 and 11, respectively, when the locomotive model operated at rated power.

A higher-frequency $(2150 \mathrm{~Hz}, 43 \mathrm{rd})$ resonance occurs in the shorter TPSS section, when using the PS-PWM. Figs. 10(a) and (c) show that $v_{p}$ is severely distorted and rich in 43rd harmonic $(3.99 \mathrm{kV})$. The THD of $v_{p}$ reaches $15.65 \%$. The waveform and spectrum of $v_{a b}$, given in Figs. 10(b) and (d), are similar to those of the former test since the fixed PWM. In this case, another sideband $(152.0 \mathrm{~V}, 43 \mathrm{rd})$ of $v_{a b}$ stimulates the resonance.

The application of the windowed SHE-PWM suppresses the resonance. In this case, the moving window is on W3 performing different switching pattern as shown in Figs. 11(b) and (d). As a result, $v_{p}$ is again less distorted, contains few harmonics and has a largely decreased THD of $3.94 \%$, see Figs. 11(a) and (c).

In this test, although the resonant harmonic is eliminated effectively through the proposed SHE-PWM, there exists a certain amount of resonant harmonic in $v_{p}$ (Fig. 11(c)). This is mainly due to the extremely high impedance at the resonant frequency. In practice, the system parameters are affected by
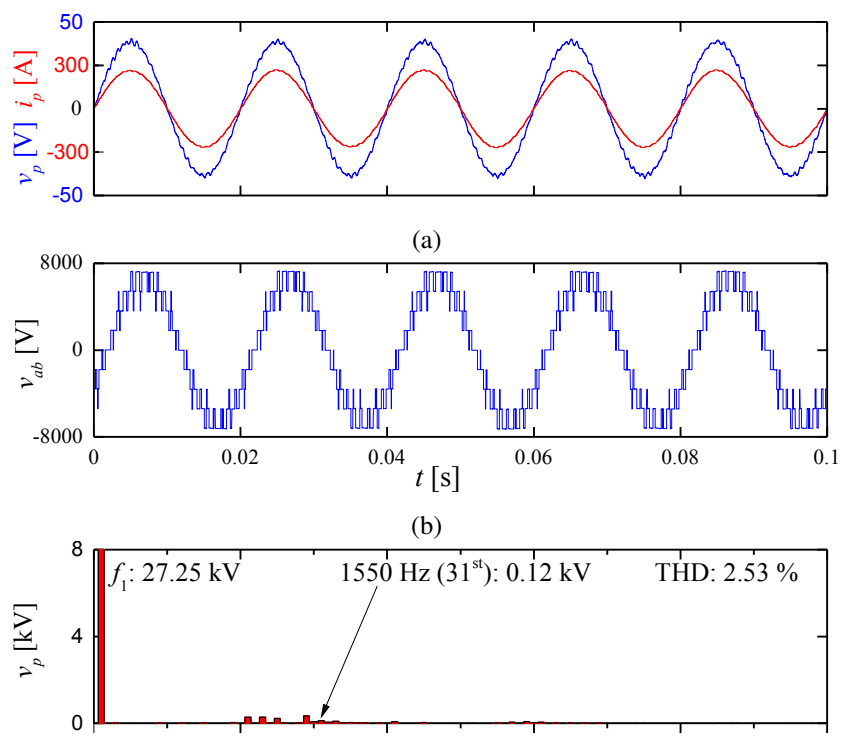

(c)

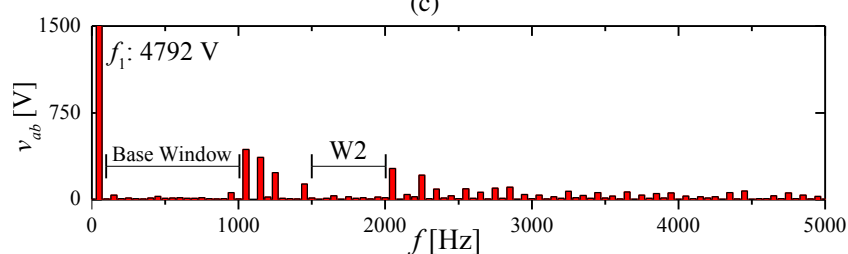

(d)

Fig. 8. Simulation result of windowed SHE-PWM: (a) waveforms of $v_{p}$ and $i_{p}$, (b) waveform of $v_{a b}$, (c) spectrum of $v_{p}$, (d) spectrum of $v_{a b}$.
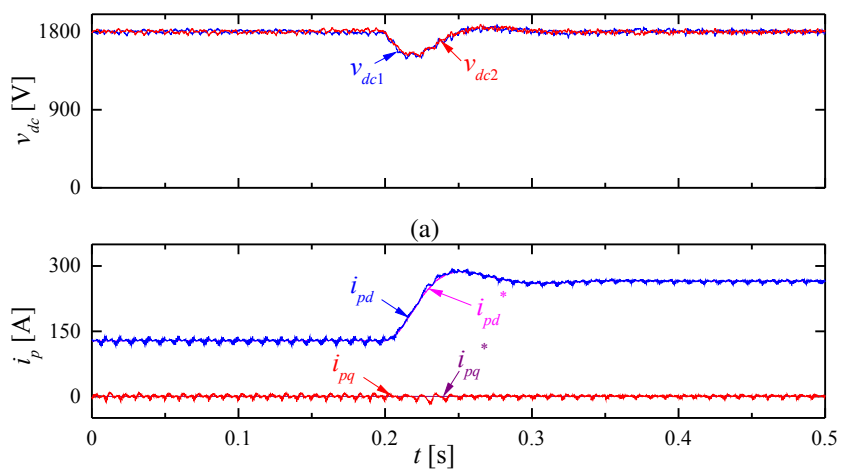

(b)

Fig. 9. Step change of the output power from half to full of the rated one: (a) waveforms of dc-link voltages, (b) waveforms of ac-side current.

some nonlinear factors, especially the skin effect of the resistance of the transmission lines. For time-domain simulation purposes, fundamental frequency parameters are provided in Table V and VI. Thus the real damping of the system in highfrequency range (including the resonant frequency) will be higher than that of the simulation model and a better harmonic performance of the proposed SHE-PWM can be expected.

It should be noted that the closed-loop implementation of SHE-PWM introduces some small low-order harmonics due to the current tracking oscillations of the controller. These are affected by the time-constant of the closed-loop control and 


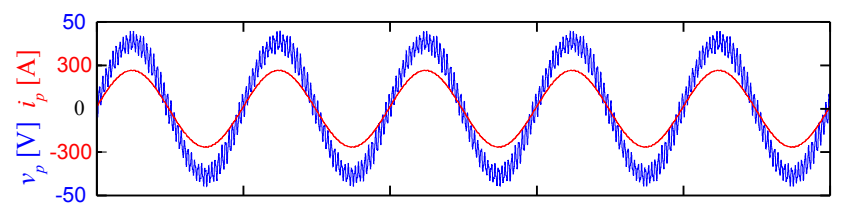

(a)

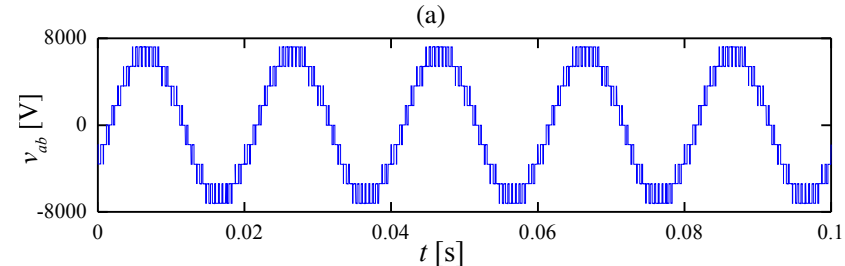

(b)

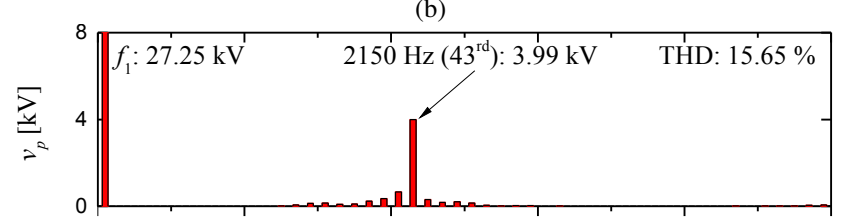

(c)

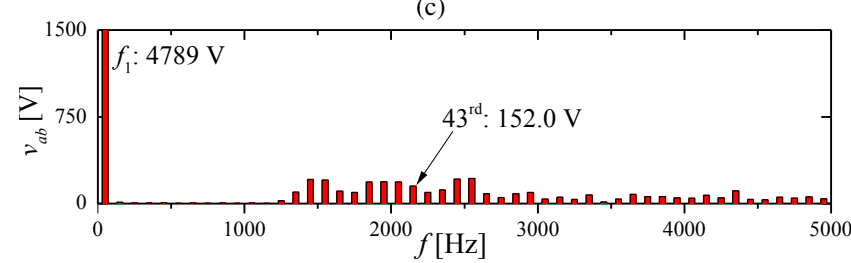

(d)

Fig. 10. Simulation result of PS-PWM, (a) waveforms of $v_{p}$ and $i_{p}$, (b) waveform of $v_{a b}$, (c) spectrum of $v_{p}$, (d) spectrum of $v_{a b}$.

achieving complete elimination has detrimental effects to the dynamic response of the controller. Even with the presence of such harmonics, the THD of the voltage remains low and the harmonics within the two windows are eliminated effectively for the purpose of resonance suppression.

\section{B. Experimental Verification of the Windowed SHE-PWM}

The windowed SHE-PWM method has been further validated on an experimental prototype, consisting of $4 \mathrm{H}$-bridge converters and a resonant circuit, as shown in Fig. 12(a), controlled with a dSPACE1007 platform. Firstly, solutions of the windowed SHE-PWM are tested by $4 \mathrm{H}$-bridge converters with a normal RL load, then, the resonance suppression performance of the proposed method is evaluated by applying the SHE voltage on a resonant circuit and comparing with PS-PWM.

1) Verification of the solutions of windowed SHE-PWM: Using W3, M $=0.71$, the SHE patterns of the $4 \mathrm{H}$-bridges are presented in Fig. 13(a), and the waveform and spectrum of the combined voltage, $v_{P W M}$, are given in Fig. 13(b). It should be noted that $v_{P W M}$ is generated by connecting the 4 outputs of the H-bridges in series as a five-winding transformer is not readily in our laboratories. Harmonics in the base window (up to $1000 \mathrm{~Hz}$ ) and the moving window (W3, from 2000 to $2500 \mathrm{~Hz}$ ) are completely eliminated. The three-level voltages of the H-bridges have 5 transitions per QW and the patterns
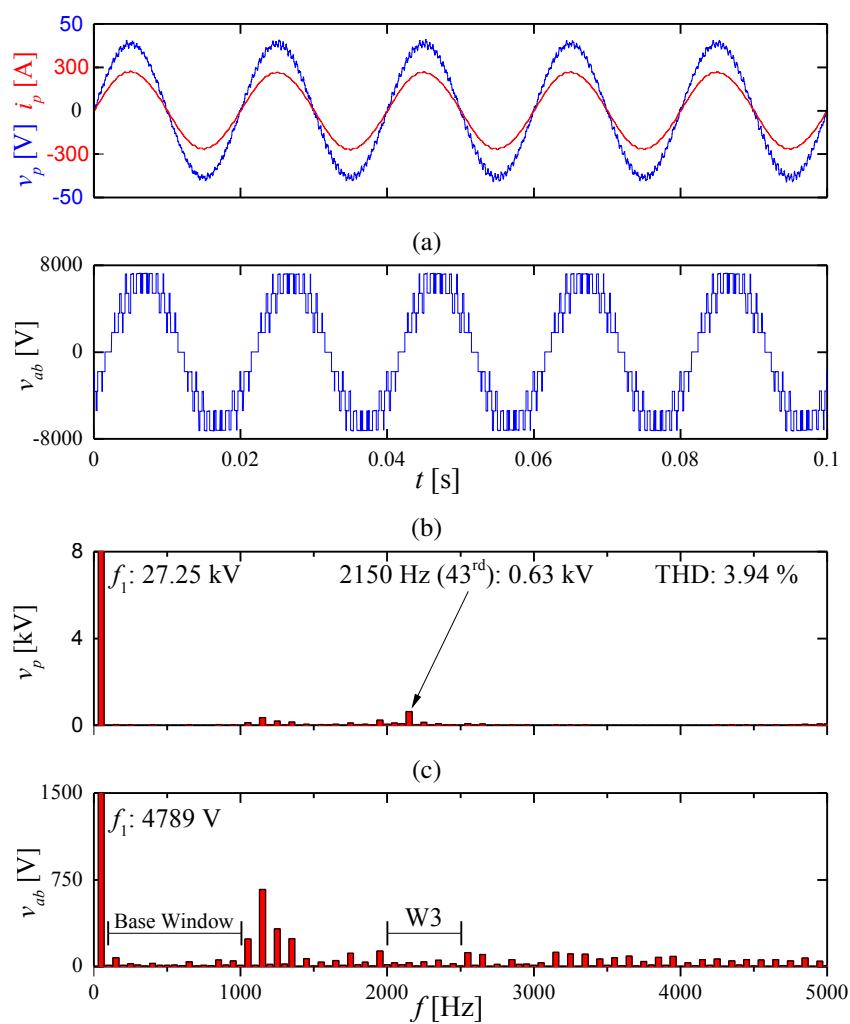

(d)

Fig. 11. Simulation result of windowed SHE-PWM: (a) waveforms of $v_{p}$ and $i_{p}$, (b) waveform of $v_{a b}$, (c) spectrum of $v_{p}$, (d) spectrum of $v_{a b}$.

are rotated among the bridges along the fundamental period. Similar experimental results of other windows with different modulation indexes are given in Figs. 13(c) and (d). The experimental results show that the proposed method tightly control the harmonics in the windows providing potentially a capability to avoid some resonant frequencies.

2) Resonance suppression performance of the windowed SHE-PWM: To validate the resonance suppression capability of the proposed method, a simplified model of the distributed locomotive-TPSS coupling impedance system is constructed using an RLC resonant circuit, as shown in Fig. 12(b). On the network side, $Z_{s}, Z_{l}$ and $G_{l}$ are two $5.5 \mathrm{mH}$ reactors and $0.67 \mu \mathrm{F}$ capacitor (with their parasitic parameters), standing for the equivalent impedance in the ESS, the line impedance and line to ground admittance of the feeding lines, respectively. A $14.3 \Omega$ power resistor, $r_{o}$, is connected in the circuit to consume the power and then protect all the elements. On the locomotive side, $Z_{L}^{\prime}$ is a $21 \mathrm{mH}$ reactor (with parasitic resistance), that represents the impedance of the transformer on-board the train. The combined PWM voltage, $v_{P W M}$, is applied to the circuit as a harmonic stimulation; and the voltage on the terminal between the two sides, $v_{p}^{\prime}$, is measured as an analogue of the response on the pantograph.

When PS-PWM is applied, as shown in Fig. 14(a), the waveform of $v_{p}^{\prime}$ is distorted severely. Harmonics between 2000 and $2500 \mathrm{~Hz}$ in $v_{p}^{\prime}$ are amplified apparently as the sidebands 


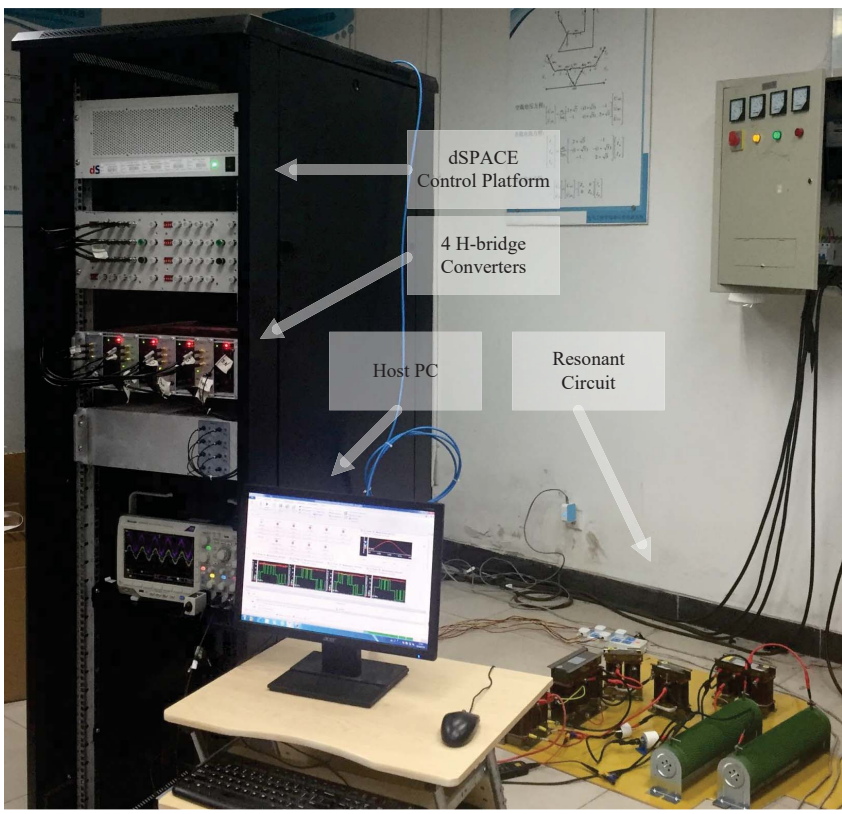

(a)

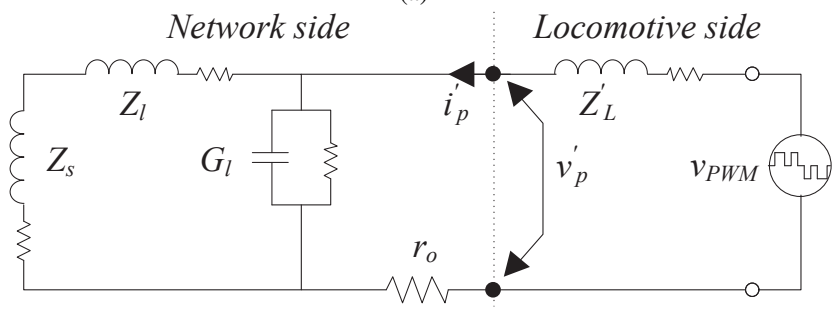

(b)

Fig. 12. Laboratory prototype: (a) photo of the overall prototype, (b) equivalent circuit diagram of the resonant circuit.

in this frequency range of $v_{P W M}$ coincide with the resonant frequency of the circuit. Although the fundamental of $v_{p}^{\prime}$ is just $88 \mathrm{~V}$, rms, the amplified resonant harmonics raise up the peak of $v_{p}^{\prime}$ to $180 \mathrm{~V}$. Alternatively, as shown in Fig. 14(b), adopting the windowed SHE-PWM with W3, the waveform of $v_{p}^{\prime}$ is much less distorted than that of PS-PWM case. The resonant harmonics with large amplitudes in $v_{p}^{\prime}$ disappeared, since the selected window covers the resonant frequency range so that $v_{P W M}$ doesn't provide the harmonic stimulation within this range. Consequently, the peak of $v_{p}^{\prime}$ decreases to only $140 \mathrm{~V}$ (22\% reduction to PS-PWM). A comparative analysis of $v_{p}^{\prime}$ spectra of Figs. 14(a) and (b) is summarized in Table III. Using PS-PWM, harmonics in the range from 2000 to 2500 $\mathrm{Hz}$ (except the $2350 \mathrm{~Hz}$ ) are more than $7.5 \mathrm{~V}$, rms, particularly, the harmonic of $2250 \mathrm{~Hz}$ goes to $12.65 \mathrm{~V}$, rms, $14.2 \%$ of the fundamental; using windowed SHE-PWM, on the contrary, harmonics in that range are no more than $0.75 \mathrm{~V}, \mathrm{rms}$, the total harmonic distortion decreases by $12.13 \%$. Some noneliminated harmonics of the windowed SHE-PWM close to the resonant frequency range exist, but their amplitudes are relatively small, generally lower than the counterparts of PSPWM.

It should be noted that the equivalent circuit consisting of lumped elements is a simplified model for the real distributed system. The frequency response of the circuit is affected by the accuracy, nonlinearity, frequency variation of the parameters of the RLC elements. Comparing with the simulation as well as the measurements in real applications, the harmonic amplification of the experimental equivalent circuit is not extremely high at the resonant frequency range and it attenuates slow. However, the experimental equivalent circuit provided a resonant point for testing and the results shown that when some sidebands of PS-PWM coincide with the resonant frequency stimulating the resonance, the windowed SHE-PWM can be an alternative to effectively suppress the resonance.

\section{CONCLUSION}

A windowed SHE-PWM method is proposed in this work for the purpose of TPSS resonance suppression. The proposed modulation scheme covers a low-frequency range as well as a window within the range of the potential resonant frequency in a TPSS section, while keeping a desired low switching frequency of the traction converters. Thanks to the proper selection of the windows and the relaxations in the formulation of the SHE-PWM problem, a wide range of continuous solutions, necessary for the closed-loop control, can be calculated and used to address the resonant frequency variation. A simulation comparison between the windowed SHE-PWM and the conventional PS-PWM proves that the windowed SHE-PWM is an effective alternative to the PSPWM for the purpose of resonance suppression. The solutions of the proposed windowed SHE-PWM are verified experimentally with the resonance suppression performance of the proposed method evaluated on an equivalent resonant circuit and compared with PS-PWM. Both simulations and experiments validate the effectiveness and feasibility of the proposed method.

The windowed SHE-PWM can be readily expanded for other locomotive topologies. For instance, one can design a $k=6$ and $N=7$ windowed SHE-PWM problem for a locomotive with 6 interleaved H-bridge 4QCs with 350 $\mathrm{Hz}$ carrier frequency. A similar approach can also be used in locomotives with different 4QC topologies, for example reformulating (4) and (5) as five-level waveforms for singlephase three-level NPC 4QCs. Despite the large computational requirements of the windowed SHE-PWM, all the formulations of the problem will be precalculated off-line. Therefore, the proposed method is flexible and easy-to-implement.

\section{APPENDIX A}

\section{MODELING OF THE ESS}

The core of the ESS is the $\mathrm{Vv}$ transformer which commonly consists of two single-phase transformers. Besides, the external 3-phase grid should be modeled in the ESS referring to threephase Thévenin theorem. In this study, $110 \mathrm{kV}$ grid and 31.5 MVA single-phase transformer are chosen for modeling the ESS, as shown in Tables IV(a) and (b), respectively. 

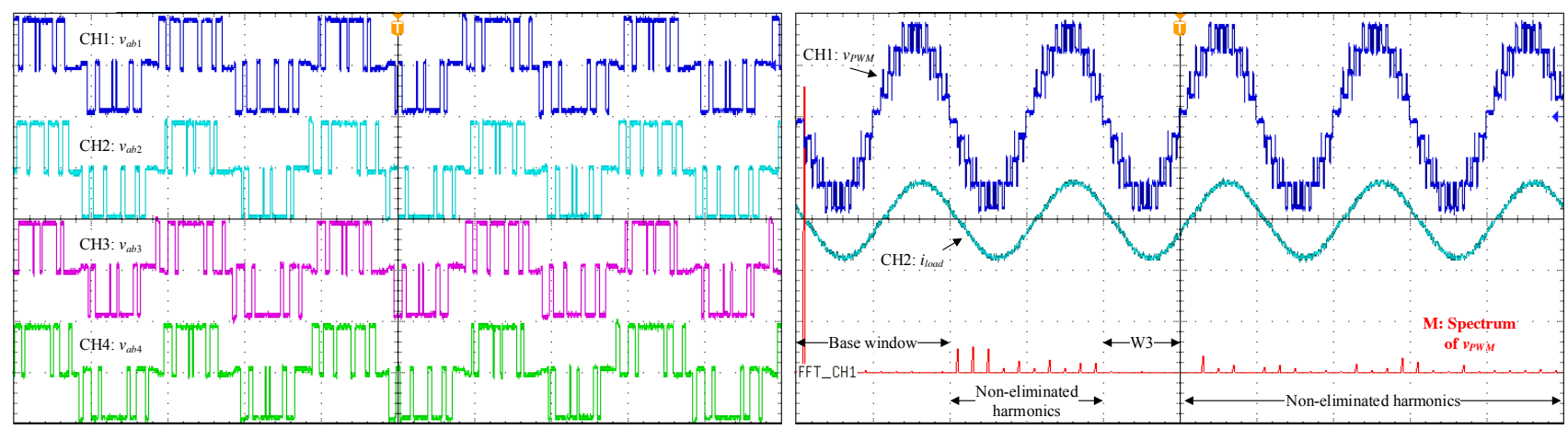

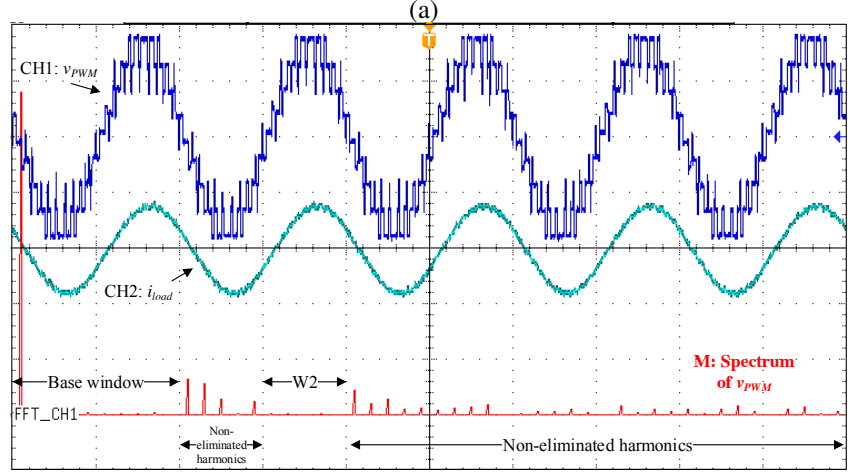

(c)

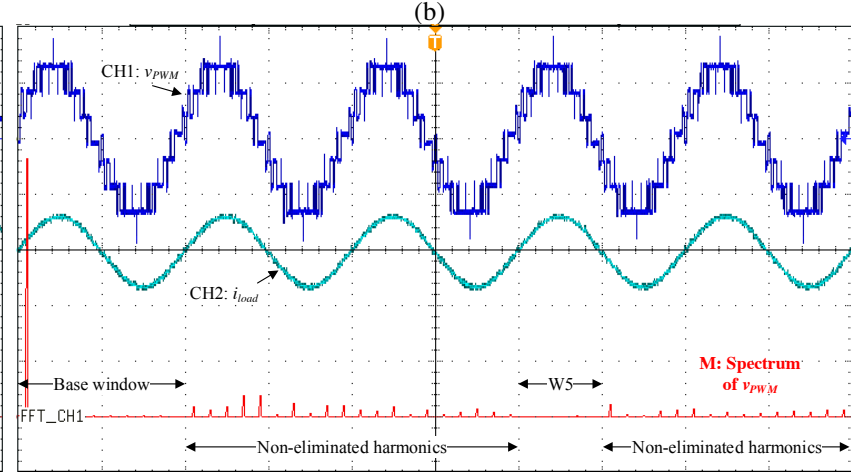

(d)

Fig. 13. Experimental result of windowed SHE-PWM: (a-b) W3, M $=0.71$, SHE patterns of the four H-bridge voltages, $v_{a b i}$, waveform and spectrum of the combined voltage, $v_{P W M}$ and waveform of the load current, $i_{\text {load }}$, (c-d) waveforms and spectra for $\mathrm{W} 2, \mathrm{M}=0.74$ and $\mathrm{W} 5, \mathrm{M}=0.6 .50 \mathrm{~V} / \mathrm{div}$ for $v_{a b i}$, $100 \mathrm{~V} / \mathrm{div}$ for $v_{P W M}, 10 \mathrm{~A} / \mathrm{div}$ for $i_{\text {load }}$ and $20 \mathrm{~V} / \mathrm{div}-\mathrm{y}, 500 \mathrm{~Hz} / \mathrm{div}-\mathrm{x}$ for spectrum.

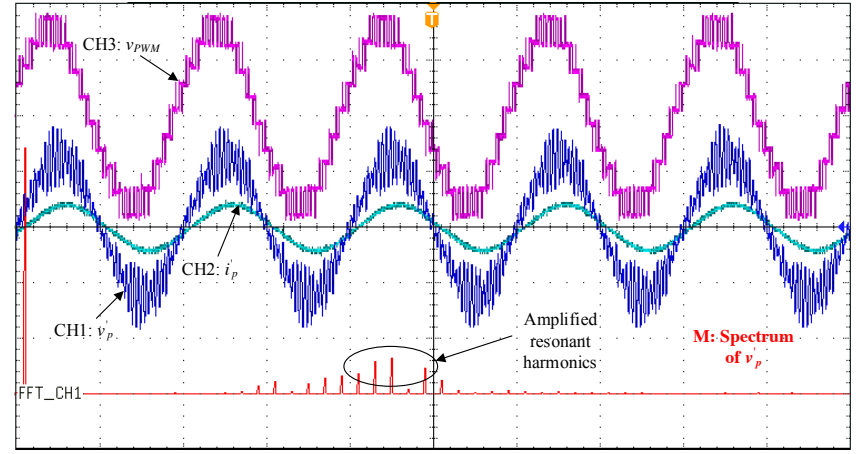

(a)

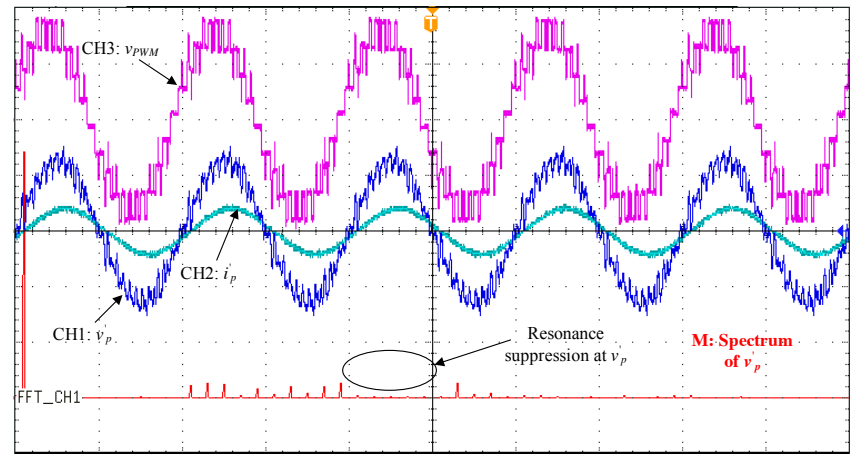

(b)

Fig. 14. Experimental result on the resonant circuit: (a) PS-PWM with $250 \mathrm{~Hz}$ carrier frequency, (b) windowed SHE-PWM with W3, M $=0.71$. CH1: $v_{p}^{\prime}$, $100 \mathrm{~V} / \mathrm{div}, \mathrm{CH} 2: i_{p}^{\prime}, 20 \mathrm{~A} / \mathrm{div}, \mathrm{CH} 3: v_{P W M}, 100 \mathrm{~V} / \mathrm{div}, \mathrm{M}$ : FFT for $\mathrm{CH} 3,20 \mathrm{~V} / \mathrm{div}-\mathrm{y}, 500 \mathrm{~Hz} / \mathrm{div}-\mathrm{x}$.

TABLE III

SPECTRUM ANALYSIS OF $v_{p}^{\prime}$ FOR PS-PWM AND WINDOWED SHE-PWM, $\S$ : PS-WPM, $\uparrow:$ WINDOWED SHE-PWM

\begin{tabular}{c|cccccccccccccc}
\hline \hline$f(\mathrm{~Hz})$ & 50 & 1750 & 1850 & 1950 & $\mathbf{2 0 5 0}$ & $\mathbf{2 1 5 0}$ & $\mathbf{2 2 5 0}$ & $\mathbf{2 3 5 0}$ & $\mathbf{2 4 5 0}$ & 2550 & 2650 & 2750 & $\mathrm{THD}$ \\
\hline$\S v_{p}^{\prime}(\mathrm{V}, \mathrm{rms})$ & 88.24 & 3.69 & 5.71 & 6.16 & $\mathbf{7 . 5 3}$ & $\mathbf{1 1 . 5 0}$ & $\mathbf{1 2 . 5 6}$ & $\mathbf{1 . 7 2}$ & $\mathbf{9 . 2 4}$ & 4.74 & 1.12 & 0.41 & $27.18 \%$ \\
$\dagger v_{p}^{\prime}(\mathrm{V}, \mathrm{rms})$ & 88.49 & 1.53 & 4.11 & 5.03 & $\mathbf{0 . 7 5}$ & $\mathbf{0 . 3 2}$ & $\mathbf{0 . 3 5}$ & $\mathbf{0 . 4 3}$ & $\mathbf{0 . 2 5}$ & 0.41 & 5.08 & 1.2 & $15.05 \%$ \\
\hline \hline
\end{tabular}

\section{APPENDIX B}

Modeling of THE FeEding Network

Fig. 15 shows the cross section of the double-track T-R+NF feeding network studied in this paper. The feeding network is a paralleled multi-conductor transmission line structure with distributed parameters of the conductors. It is generally modeled as a chain circuit model described by impedance and admittance matrices of the conductors per length unit, 
TABLE IV

ELECTRICAL PARAMETERS OF ESS

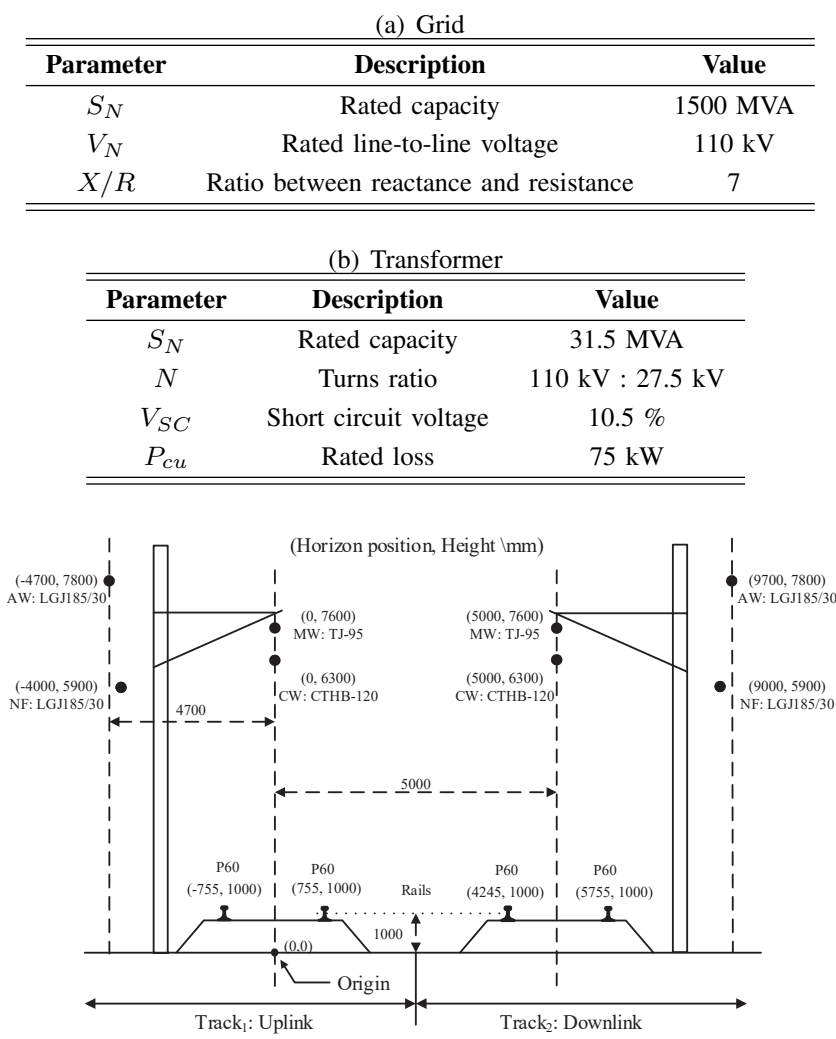

Fig. 15. Typical cross section of a double track T-R+NF feeding network. CW: contact wire, MW: messenger wire, NF: negative feeder, AW: auxiliary wire.

as documented in available technical literature, e.g. [19], [21], [32], [33]. To get a simplified model, some conductors should be combined electrically by using Carson equation resulting in a 6-line structure. For each track there are 3 lines: $\mathrm{T}$ (including $\mathrm{CW}, \mathrm{MW}$ and $\mathrm{AW}$ ), R (including two running rails) and $\mathrm{NF}$ as shown in Fig. 1. According to the geometrical positions and types of the paralleled conductors of Fig. 15, the $6 \times 6$ impedance and admittance matrices are calculated in Tables V and VI, respectively.

\section{ACKNOWLEDGMENT}

Dr. Konstantinou acknowledges the financial support received from the Australian Academy of Technological Sciences and Engineering (ATSE) and the Chinese Ministry of Science and Technology (MOST) through the Young Scientists Exchange Program (YSEP).

\section{REFERENCES}

[1] K. Sato, M. Yoshizawa, and T. Fukushima, "Traction systems using power electronics for shinkansen high-speed electric multiple units," in Proc. Int. Power Electron. Conf., Jun. 2010, pp. 2859-2866.

[2] T. Uzuka, "Faster than a speeding bullet: An overview of japanese high-speed rail technology and electrification," IEEE Electrification Magazine, vol. 1, no. 1, pp. 11-20, Sep. 2013
[3] X. Huang, L. Zhang, M. He, X. You, and Q. Zheng, "Power electronics used in chinese electric locomotives," in Proc. IEEE Int. Power Electron. and Motion Control Conf., May 2009, pp. 1196-1200.

4] H.-S. Song, R. Keil, P. Mutschler, J, van der Weem, and K. Nam, "Advanced control scheme for a single-phase pwm rectifier in traction applications," in Proc. Annu. Meeting, Ind. Appl. Conf., vol. 3, Oct. 2003, pp. $1558-1565$ vol.3.

[5] G. G. Balazs, M. Horvath, I. Schmidt, and P. Kiss, "Examination of new current control methods for modern pwm controlled ac electric locomotives," in Proc. IET Int. Conf. Power Electron., Machines and Drives, Mar. 2012, pp. 1-5.

[6] S. Gazafrudi, A. Tabakhpour Langerudy, E. Fuchs, and K. Al-Haddad, "Power quality issues in railway electrification: A comprehensive perspective," IEEE Trans. Ind. Electron., vol. 62, no. 5, pp. 3081-3090, May 2015.

[7] W. Song, J. Ma, L. Zhou, and X. Feng, "Deadbeat predictive power control of single-phase three-level neutral-point-clamped converters using space-vector modulation for electric railway traction," IEEE Trans. Power Electron., vol. PP, no. 99, pp. 1-1, 2015.

[8] L. He, J. Xiong, H. Ouyang, P. Zhang, and K. Zhang, "High-performance indirect current control scheme for railway traction four-quadrant converters," IEEE Trans. Ind. Electron., vol. 61, no. 12, pp. 6645-6654, Dec. 2014.

[9] A. Steimel, "Electric railway traction in europe," IEEE Ind. Appl. Mag., vol. 2, no. 6, pp. 6-17, Nov. 1996.

[10] S. Kejian, W. Mingli, V. Agelidis, and W. Hui, "Line current harmonics of three-level neutral-point-clamped electric multiple unit rectifiers: analysis, simulation and testing," IET Power Electron., vol. 7, no. 7, pp. 1850-1858, Jul. 2014.

[11] X. Chu, F. Lin, and Z. Yang, "The analysis of time-varying resonances in the power supply line of high speed trains," in Proc. Int. Power Electron. Conf., May 2014, pp. 1322-1327.

[12] Y. Xiong, Y. Zhang, and D. Tong, "Analysis on harmonic current of electrified railway traction network based on multi-port reduced-order model," in Proc. China Int. Conf. Electricity Distribution, Sep. 2012, pp. 1-6.

[13] H. Hu, Z. He, and S. Gao, "Passive filter design for china highspeed railway with considering harmonic resonance and characteristic harmonics," IEEE Trans. Power Del., vol. 30, no. 1, pp. 505-514, Feb. 2015.

[14] J. Holtz and H. J. Kelin, "The propagation of harmonic currents generated by inverter-fed locomotives in the distributed overhead supply system," IEEE Trans. Power Electron., vol. 4, no. 2, pp. 168-174, Apr. 1989

[15] J. Holtz and J. O. Krah, "On-line identification of the resonance conditions in the overhead supply line of electric railways," Archiv $\mathrm{Fr}$ Elektrotechnik, vol. 74, no. 1, pp. 99-106, 1990.

[16] J. Holtz and J. O. Krah, "Adaptive optimal pulse-width modulation for the line-side converter of electric locomotives," IEEE Trans. Power Electron., vol. 7, no. 1, pp. 205-211, Jan. 1992.

[17] J. O. Krah and J. Holtz, "Total compensation of line-side switching harmonics in converter-fed ac locomotives," IEEE Trans. Ind. Appl., vol. 31, no. 6, pp. 1264-1273, Nov. 1995.

[18] H. Cui, W. Song, H. Fang, X. Ge, and X. Feng, "Resonant harmonic elimination pulse width modulation-based high-frequency resonance suppression of high-speed railways," IET Power Electron., vol. 8, no. 5, pp. 735-742, May 2015.

[19] H. Lee, C. Lee, G. Jang, and S. hyuk Kwon, "Harmonic analysis of the korean high-speed railway using the eight-port representation model," IEEE Trans. Power Del., vol. 21, no. 2, pp. 979-986, Apr. 2006.

[20] A. Dolara, M. Gualdoni, and S. Leva, "Impact of high-voltage primary supply lines in the $2 \times 25 \mathrm{kv}-50 \mathrm{hz}$ railway system on the equivalent impedance at pantograph terminals," IEEE Trans. Power Del., vol. 27, no. 1, pp. 164-175, Jan. 2012.

[21] Z. He, H. Hu, Y. Zhang, and S. Gao, "Harmonic resonance assessment to traction power-supply system considering train model in china highspeed railway," IEEE Trans. Power Del., vol. 29, no. 4, pp. 1735-1743, Aug. 2014.

[22] H. Lee, G. Kim, S. Oh, and C. Lee, "Optimal design for power quality of electric railway," in Proc. Int. Joint Conf. SICE-ICASE, Oct. 2006, pp. 3864-3869.

[23] W. Mingli, Z. Huang, S. Yang, Z. Chu, and M. Liu, "Suppression device for higher-order harmonic resonance and transient over-voltage in traction network," in CHN Patent: ZL 200710120620.9 , Sep. 2007. 
TABLE V

Self and Mutual Impedance Matrix of the Transmission Lines, $\Omega / \mathrm{km}$.

\begin{tabular}{c|cccccc}
\hline \hline & T1 & R1 & NF1 & T2 & R2 & NF2 \\
\hline T1 & $0.1057+\mathrm{j} 0.4874$ & $0.0497+\mathrm{j} 0.3086$ & $0.0488+\mathrm{j} 0.3567$ & $0.0491+\mathrm{j} 0.2992$ & $0.0495+\mathrm{j} 0.2903$ & $0.0480+\mathrm{j} 0.2838$ \\
$\mathbf{R 1}$ & $0.0497+\mathrm{j} 0.3086$ & $0.1068+\mathrm{j} 0.5409$ & $0.0490+\mathrm{j} 0.3140$ & $0.0495+\mathrm{j} 0.2903$ & $0.0498+\mathrm{j} 0.3284$ & $0.0485+\mathrm{j} 0.2850$ \\
$\mathbf{N F 1}$ & $0.0488+\mathrm{j} 0.3567$ & $0.0490+\mathrm{j} 0.3140$ & $0.2066+\mathrm{j} 0.7320$ & $0.0480+\mathrm{j} 0.2838$ & $0.0485+\mathrm{j} 0.2850$ & $0.0473+\mathrm{j} 0.2726$ \\
T2 & $0.0491+\mathrm{j} 0.2992$ & $0.0495+\mathrm{j} 0.2903$ & $0.0480+\mathrm{j} 0.2838$ & $0.1057+\mathrm{j} 0.4874$ & $0.0497+\mathrm{j} 0.3086$ & $0.0488+\mathrm{j} 0.3567$ \\
$\mathbf{R 2}$ & $0.0495+\mathrm{j} 0.2903$ & $0.0498+\mathrm{j} 0.3284$ & $0.0485+\mathrm{j} 0.2850$ & $0.0497+\mathrm{j} 0.3086$ & $0.1068+\mathrm{j} 0.5408$ & $0.0490+\mathrm{j} 0.3140$ \\
NF2 & $0.0480+\mathrm{j} 0.2838$ & $0.0485+\mathrm{j} 0.2850$ & $0.0473+\mathrm{j} 0.2726$ & $0.0488+\mathrm{j} 0.3567$ & $0.0490+\mathrm{j} 0.3140$ & $0.2066+\mathrm{j} 0.7320$ \\
\hline \hline
\end{tabular}

TABLE VI

Self and Mutual Admittance Matrix of the Transmission Lines, $10^{-5} \mathrm{~S} / \mathrm{km}$.

\begin{tabular}{c|cccccc}
\hline \hline & T1 & R1 & NF1 & T2 & R2 & NF2 \\
\hline T1 & $0.0000+\mathrm{j} 0.5643$ & $0.0000-\mathrm{j} 0.0567$ & $0.0000-\mathrm{j} 0.1057$ & $0.0000-\mathrm{j} 0.0940$ & $0.0000-\mathrm{j} 0.0256$ & $0.0000-\mathrm{j} 0.0135$ \\
R1 & $0.0000-\mathrm{j} 0.0567$ & $1000.0+\mathrm{j} 1.0403$ & $0.0000-\mathrm{j} 0.0209$ & $0.0000-\mathrm{j} 0.0256$ & $0.0000-\mathrm{j} 0.0393$ & $0.0000-\mathrm{j} 0.0043$ \\
NF1 & $0.0000-\mathrm{j} 0.1057$ & $0.0000-\mathrm{j} 0.0209$ & $0.0000+\mathrm{j} 0.2706$ & $0.0000-\mathrm{j} 0.0135$ & $0.0000-\mathrm{j} 0.0043$ & $0.0000-\mathrm{j} 0.0022$ \\
T2 & $0.0000-\mathrm{j} 0.0940$ & $0.0000-\mathrm{j} 0.0256$ & $0.0000-\mathrm{j} 0.0135$ & $0.0000+\mathrm{j} 0.5643$ & $0.0000-\mathrm{j} 0.0567$ & $0.0000-\mathrm{j} 0.1057$ \\
$\mathbf{R 2}$ & $0.0000-\mathrm{j} 0.0256$ & $0.0000-\mathrm{j} 0.0393$ & $0.0000-\mathrm{j} 0.0043$ & $0.0000-\mathrm{j} 0.0567$ & $1000.0+\mathrm{j} 1.0403$ & $0.0000-\mathrm{j} 0.0209$ \\
NF2 & $0.0000-\mathrm{j} 0.0135$ & $0.0000-\mathrm{j} 0.0043$ & $0.0000-\mathrm{j} 0.0022$ & $0.0000-\mathrm{j} 0.1057$ & $0.0000-\mathrm{j} 0.0209$ & $0.0000+\mathrm{j} 0.2706$ \\
\hline \hline
\end{tabular}

[24] T. Maeda, T. Watanabe, A. Mechi, T. Shiota, and K. Iida, "A hybrid single-phase power active filter for high order harmonics compensation in converter-fed high speed trains," in Proc. Conf. Power Conversion, vol. 2, Aug. 1997, pp. 711-717 vol.2.

[25] A. Bueno, J. M. Aller, J. A. Restrepo, R. Harley, and T. G. Habetler, "Harmonic and unbalance compensation based on direct power control for electric railway systems," IEEE Trans. Power Electron., vol. 28, no. 12, pp. 5823-5831, Dec. 2013.

[26] G. Konstantinou, V. G. Agelidis, and J. Pou, "Interleaved selective harmonic elimination pwm for single-phase rectifiers in traction applications," in Proc. IEEE Annu. Conf. Ind. Electron. Soc., Nov. 2013, pp. 930-935.

[27] H. S. Patel and R. G. Hoft, "Generalized techniques of harmonic elimination and voltage control in thyristor inverters: Part i-harmonic elimination," IEEE Trans. Ind. Appl., vol. IA-9, no. 3, pp. 310-317, May 1973.

[28] M. S. A. Dahidah, G. Konstantinou, and V. G. Agelidis, "A review of multilevel selective harmonic elimination pwm: Formulations, solving algorithms, implementation and applications," IEEE Trans. Power Electron., vol. 30, no. 8, pp. 4091-4106, Aug. 2015.

[29] G. Konstantinou, V. G. Agelidis, and J. Pou, "Theoretical considerations for single-phase interleaved converters operated with she-pwm," IEEE Power Electron. Lett., vol. 29, no. 10, pp. 5124-5128, Oct. 2014.

[30] M. Ebrahimi, S. A. Khajehoddin, and M. Karimi-Ghartemani, "Fast and robust single-phase dq current controller for smart inverter applications," IEEE Trans. Power Electron., vol. 31, no. 5, pp. 3968-3976, May 2016.

[31] U. A. Miranda, L. G. B. Rolim, and M. Aredes, "A dq synchronous reference frame current control for single-phase converters," in Proc. IEEE Power Electron. Spec. Conf., Jun. 2005, pp. 1377-1381.

[32] W. Mingli, C. Roberts, and S. Hillmansen, "Modelling of ac feeding systems of electric railways based on a uniform multi-conductor chain circuit topology," in Proc. IET Conf. Railway Traction Systems, Apr. 2010, pp. $1-5$

[33] A. Mariscotti, P. Pozzobon, and M. Vanti, "Distribution of the traction return current in at electric railway systems," IEEE Trans. Power Del., vol. 20, no. 3, pp. 2119-2128, Jul. 2005.

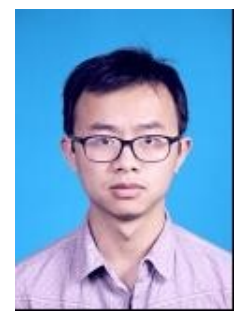

Kejian Song was born in Hunan province, China, on January 8, 1988. He received his B.Sc. degree in electrical engineering from Shaoyang University, Shaoyang, China in 2010 and his M.Sc. degree in electrical engineering from Beijing Jiaotong University (BJTU), Beijing, China in 2012. His is currently working toward his $\mathrm{PhD}$ degree in electrical engineering at BJTU. From December 2014 to December 2015 he was with the Australia Energy Research Institute (AERI), UNSW Australia, Sydney as an exchanged $\mathrm{PhD}$ student sponsored by China Scholarship Council (CSC). His research interests include modulation methods and control strategies for traction converters and electric power quality of traction power supply systems.

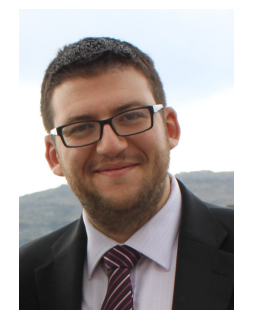

Georgios Konstantinou (S'08-M'11) received the B.Eng. degree in electrical and computer engineering from the Aristotle University of Thessaloniki, Thessaloniki, Greece, in 2007 and the Ph.D. degree in electrical engineering from UNSW Australia, Sydney, in 2012. From 2012 to 2015 he was a Research Associate at UNSW Australia where he is currently a Lecturer with the School of Electrical Engineering and Telecommunications. His main research interests include hybrid and modular multilevel converters, power electronics for HVDC and energy storage applications, pulse width modulation and selective harmonic elimination techniques for power electronics. 


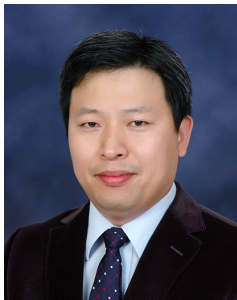

Wu Mingli was born in Hebei province, China, on November 11, 1971. He received his B.Sc. and M.Sc. degrees in electrical engineering from Southwest Jiaotong University, Chengdu, China in 1993 and 1996, respectively, and his Ph.D. degree in electrical engineering from Beijing Jiaotong University (BJTU), Beijing, China in 2006. Since 2008, he has been a Professor at the School of Electrical Engineering, BJTU. His research interests include power supply for electric railways, digital simulation of power systems and electric power quality.

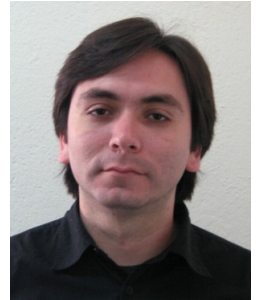

Ricardo P. Aguilera (S'01-M12) received his B.Sc. degree in electrical engineering from the Universidad de Antofagasta, Chile, in 2003; his M.Sc. degree in electronics engineering from the Universidad Tecnica Federico Santa Maria (UTFSM), Chile, in 2007; and his Ph.D. degree in Electrical Engineering from The University of Newcastle (UoN), Australia, in 2012. From 2012 to 2013, he was a Research Academic at UoN, where he was part of the Centre for Complex Dynamic Systems and Control. From 2014 to 2016, he was a Senior Research Associate at The University of New South Wales (UNSW), Australia, where he was part of the Australian Energy Research Institute (AERI). Since Sep 2016, he is with the School of Electrical, Mechanical and Mechatronic Systems, at the University of Technology Sydney (UTS), Australia, where he currently holds a Lecturer position. His main research interests include power electronics, renewable energy, and theoretical and practical aspects on model predictive control.

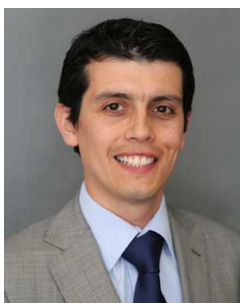

Pablo Acuna (M'12) received the B.S. in Electronics Engineering, the Electronics Engineering Professional degree, and the Ph.D. degree in Electrical Engineering from the University of Concepción, Chile, in 2004, 2007, and 2013 respectively. He is currently Research Associate at the School of Electrical Engineering and Telecommunications, University of New South Wales, Sydney, Australia. His research interests include electrical power conversion systems and its applications to industry, transportation and utility.

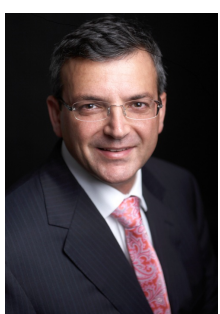

Vassilios G. Agelidis (S89M91SM00F16) was born in Serres, Greece. He received the B.Eng. degree in electrical engineering from the Democritus University of Thrace, Thrace, Greece, in 1988, the M.S. degree in applied science from Concordia University, Montreal, QC, Canada, in 1992, and the Ph.D. degree in electrical engineering from Curtin University, Perth, Australia, in 1997. He has worked at Curtin University (19931999), University of Glasgow, U.K (20002004), Murdoch University, Perth, Australia (20052006), the University of Sydney, Australia (20072010), and the University of New South Wales (UNSW), Sydney, Australia (2010-2016). He is currently a professor at the Department of Electrical Engineering, Technical University of Denmark. Dr. Agelidis received the Advanced Research Fellowship from the U.K.s Engineering and Physical Sciences Research Council in 2004. He was the Vice-President Operations within the IEEE Power Electronics Society from 2006 to 2007. He was an AdCom Member of the IEEE Power Electronics Society from 2007 to 2009 and the Technical Chair of the 39th IEEE Power Electronics Specialists Conference, Rhodes, Greece, 2008. 